\title{
Effect of Prostacyclin on Pulmonary Ischemia-reperfusion Injury according to the State of Lung Inflation
}

\author{
Department of Anesthesiology and Pain Medicine, Sanggye Paik Hospital, Inje University College of Medicine, Seoul, Korea \\ *Department of Anesthesiology and Pain Medicine, Seoul National University Bundang Hospital, Seongnam, Korea
}

\author{
Kyemin Kim, M.D., and Yong-Seok Oh, M.D.*
}

Background: Prostacyclin $\left(\mathrm{PGI}_{2}\right)$ is a commonly used protective agent against pulmonary ischemia-reperfusion injury. In this study, it was postulated that the protective effect of $\mathrm{PGI}_{2}$ on pulmonary ischemia-reperfusion injury would differ according to the state of pulmonary expansion during ischemic injury.

Methods: Under general anesthesia, left pulmonary ischemia was induced by occluding the left hilum in 40 New Zealand white rabbits. They were allocated to four groups $(\mathrm{n}=10$ in each group). In groups I and II, ischemia was started with lungs inflated, and in groups III and IV, ischemia was started with lungs collapsed. $\mathrm{PGI}_{2}$ was infused only in groups II and IV at $250 \mathrm{ng} / \mathrm{kg} / \mathrm{min}$ for 20 minutes just before and after the ischemic period. After 60 minutes of ischemia, reperfusion was maintained for 2 hours, and then the left lung was resected. ABGA and lung water fraction were measured to assess the severity of the ischemia-reperfusion injury.

Results: Compared to groups I and II, $\mathrm{PaO}_{2}$ decreased markedly in group III and moderately in group IV (P $\left.<0.05\right)$. The $\mathrm{PaCO}_{2}$ of groups III and IV significantly differed from those of groups I and II $(\mathrm{P}<0.05)$. The percent changes in lung water fraction were significantly higher in group III than in the other groups $(\mathrm{P}<0.05)$.

Conclusions: $\mathrm{PGI}_{2}$ infused before and after pulmonary ischemia produced a significant protective effect on ischemia- reperfusion injury in the collapsed lung group. In the expanded lung group, however, the effect of $\mathrm{PGI}_{2}$ was masked by lung expansion, which itself led to excellent pulmonary preservation against ischemia-reperfusion injury. (Korean $\mathbf{J}$ Anesthesiol 2004; 46: S 10 S 16)

Key Words: epoprostenol, ischemia-reperfusion injury, lung transplantation, prostaglandins.

\section{INTRODUCTION}

Ischemia-reperfusion injury is a serious problem which can occur during lung transplantation. Preservation of pulmonary function by reducing ischemia-reperfusion injury is essential for successful lung transplantation. Although the mechanisms responsible for ischemia-reperfusion lung injury are not clear yet, it is commonly accepted that ischemic time, storage conditions and additive usage of some pharmacologic agents are responsible for the severity of ischemia-reperfusion lung injury. There have been numerous investigations about the effective methods to ameliorate ischemia-

Received : June 25, 2003

Corresponding to : Kyemin Kim, Department of Anesthesiology and Pain Medicine, Inje University Sanggye Paik Hospital, 761-1 Sanggye 7-dong, Nowon-gu, Seoul 139-707, Korea. Tel: 02-950-1168, Fax: 02-950-1323, E-mail: kyemin@sanggyepaik.ac.kr

This work was supported by the 2002 Inje University Research Grant. reperfusion injury. ${ }^{1-7)}$

In the present study, we focused on the effectiveness of prostacyclin $\left(\mathrm{PGI}_{2}\right)$ and lung expansion in reducing pulmonary ischemia-reperfusion injury. The state of inflation of donor lung has been reported to play important role in reducing ischemiareperfusion injury. ${ }^{2,3} \mathrm{PGI}_{2}$, which can be employed with single flush perfusion, has recently been used by many centers and has been proven to provide favorable results. ${ }^{4)}$

We postulated that the effectiveness of $\mathrm{PGI}_{2}$ would be different according to the application of pulmonary inflation. We evaluated the individual and combined effects of lung expansion and intravenous infusion of $\mathrm{PGI}_{2}$ in warm ischemia- reperfusion model. The severity of ischemia-reperfusion injury was assessed by means of pulmonary oxygenation and lung water fraction.

\section{MATERIALS AND METHODS}

Forty male New Zealand white rabbits weighing 2-4 kg were 
used. The cases in which baseline arterial oxygen tension was less than $350 \mathrm{mmHg}\left(\mathrm{F}_{\mathrm{I}} \mathrm{O}_{2}=1.0\right)$ were excluded from this study. All procedures conformed to the Guiding Principles in the Care and Use of Animals of the American Physiological Society, and were performed in compliance with the Guide for the Care and Use of Laboratory Animals prepared by the National Academy of Science and published by the National Institutes of Health (NIH Publication revised 1996).

The rabbits were divided into four groups $(n=10$ in each group): group I, II, III and IV. General anesthesia was induced with isoflurane in oxygen. After loss of consciousness, an intravenous catheter was inserted into an earlobe vein and atropine $0.1 \mathrm{mg}$ was administered intravenously. Normal saline was infused at the rate of $5 \mathrm{ml} / \mathrm{kg} / \mathrm{hr}$ throughout the procedure. After tracheostomy, an endotracheal tube (internal diameter: $3.0 \mathrm{~mm}$ ) was put in place and the animals were ventilated mechanically with $100 \%$ oxygen using a volume controlled ventilator (model No. 683, Harvard Apparatus, USA). Vecuronium $0.2 \mathrm{mg} / \mathrm{kg}$ was administered intravenously and infused at the rate of $1 \mathrm{mg} / \mathrm{hr}$. Minute ventilation was adjusted to maintain $\mathrm{PaCO}_{2}$ in the range of 35 to $45 \mathrm{mmHg}$ during pre-ischemic period. The femoral artery was cannulated to monitor arterial pressure continuously. Rectal temperature was monitored and maintained in the range of 37 $38^{\circ} \mathrm{C}$ using a homeothermic blanket control unit (Harvard apparatus, USA).

Horizontal thoracotomy was performed through the sixth intercostal space in supine position. The right postcaval lobe was resected to obtain a pre-ischemic lung water fraction. $100 \mathrm{U} / \mathrm{kg}$ of heparin was administered to inhibit the formation of a thrombus.

In groups II and IV, $\mathrm{PGI}_{2}\left(\mathrm{PGI}_{2} \cdot \mathrm{Na}{ }^{\circledR}\right.$, Biomol, USA) was infused intravenously at the rate of $250 \mathrm{ng} / \mathrm{kg} / \mathrm{min}$ for 20 minutes before ischemia. Just before inducing ischemia, both lungs were inflated at $20 \mathrm{cmH}_{2} \mathrm{O}$ with $100 \%$ oxygen for one minute in groups I and II. In groups III and IV, they were deflated by disconnecting the endotracheal tube from the breathing circuit for one minute. As soon as the left lung was expanded or collapsed for one minute according to groups, the left hilum was occluded with tape ligature to interrupt the ventilation and perfusion of left lung. The ventilation and perfusion of right lung were maintained. After 60 minutes of ischemia, the tape ligature around the left hilum was released to restore perfusion and ventilation. Because left lung was deflated almost completely at the end of ischemic period regardless of groups, positive airway pressure was applied several times to inflate the left lung at the beginning of the reperfusion. Thereafter mechanical ventilation was maintained. At the beginning of reperfusion, $\mathrm{PGI}_{2}\left(\mathrm{PGI}_{2} \cdot \mathrm{Na}{ }^{\circledR}\right.$, Biomol, USA $)$ was infused again intravenously at the rate of $250 \mathrm{ng} / \mathrm{kg} / \mathrm{min}$ for 20 minutes in groups II and IV. $\mathrm{PGI}_{2}$ was not given to group I and group III.

Measurement of mean arterial pressure and arterial blood gas analysis were carried out during baseline, at the beginning of reperfusion, and then at one hour interval. To assess the function of isolated left lung, ABGA was performed five minutes after occluding the right hilum. Following ABGA the tape ligature occluding right hilum was removed. In the case of severe metabolic acidosis (base excess $>14 \mathrm{mEq} / \mathrm{L}$ ) sodium bicarbonate was administered intravenously. Tidal volume was maintained constantly throughout experiment. However respiratory rates were adjusted when $\mathrm{PaCO}_{2}$ increased above $50 \mathrm{mmHg}$. End-tidal concentration of isoflurane was measured using anesthetic agent monitor (Capnomac. Datex instrumenttarium Corp., Finland).

Two hours after the beginning of reperfusion, the left lung was resected. Blood was drained naturally and the wet weight of left lung was measured. The left lung was desiccated for 7 days at $80^{\circ} \mathrm{C}$ and then dry weight was measured on electronic balance (Precision Electronic Balance, A\&D Co. LTD., Japan). The same process had been performed on the right postcaval lobe, which was resected before the ischemic period. Lung water fraction was calculated from the difference between the wet and dry weights as follows.

$$
\begin{aligned}
\text { Lung water fraction }(\%)= & ([\text { wet weight-dry weight }] / \text { wet } \\
& \text { weight }) \times 100
\end{aligned}
$$

To determine the extent of increase in lung water fraction after ischemia-reperfusion injury, percent changes in lung water fraction were calculated as follows.

Percent change $(\%)=([$ left lung water fraction-right postcaval lobe water fraction]/ right postcaval lobe water fraction) $\times 100$

Data are presented as the mean $\pm \mathrm{SD}$. All statistical analysis was processed using SPSS (version 10.0). Body weights, tidal volume were compared among groups using the Kruskal- Wallis test. Mean arterial pressure, respiratory rates, end tidal concentration of isoflurane and the data of arterial blood gas were analyzed by repeated measures ANOVA with multiple comparisons (Duncan). The water fraction of lung and percent changes in water fraction were compared among groups with one-way ANOVA with multiple comparisons (Duncan). Significance was determined when $\mathrm{P}$ value was less than 0.05 .

\section{RESULTS}

There was no difference among groups in weight and mean 
arterial pressure (Table 1). In tidal volume, respiratory rates and end-tidal concentration of isoflurane, there was no difference among groups (Table 2).

The results of ABGA showed the tendency to decrease in $\mathrm{pH}$ and $\mathrm{PaO}_{2}$ and to increase in $\mathrm{PaCO}_{2}$ during reperfusion period (Table 3). The severity of these responses was different among the groups. The severest response occurred in group III, followed by group IV. In contrast, the function of gas exchange in groups I and II was relatively well maintained.

The comparison of arterial $\mathrm{pH}$ among all groups showed no difference. However, the values of $\mathrm{PaCO}_{2}$ and $\mathrm{PaO}_{2}$ were significantly different among the groups. The $\mathrm{PaCO}_{2}$ values in groups III and IV were higher than those obtained in groups I and II $(\mathrm{P}<0.05)$. The $\mathrm{PaCO}_{2}$ values of group III were also higher than those of group IV $(\mathrm{P}<0.05)$. The $\mathrm{PaO}_{2}$ values measured during reperfusion period in groups I and II were maintained at pre-ischemic values, and there was no difference between groups I and II. On the other hand, there were significant differences when comparing the expansion groups (groups I and II) with the collapse groups (groups III and IV) $(\mathrm{P}<0.05)$. The $\mathrm{PaO}_{2}$ values of group III were lower than those of group IV $(\mathrm{P}<0.05)$. During the reperfusion period severe hypoxemia occurred invariably in group III, while individual variation in $\mathrm{PaO}_{2}$ was observed in group IV.

The percent change in lung water fraction was significantly higher in group III than it was in the other groups (Table 4). Frothy secretion supposedly related to pulmonary edema formation was noticed in four rabbits in group III and one rabbit in group IV during the reperfusion period.

Table 1. Weight and Mean Arterial Pressure

\begin{tabular}{lcccc}
\hline & Group I & Group II & Group III & Group IV \\
\hline Weight (kg) & $2.8 \pm 0.3$ & $2.7 \pm 0.2$ & $2.8 \pm 0.3$ & $2.9 \pm 0.5$ \\
MAP (mmHg) & & & & \\
$\quad$ Baseline & $65.7 \pm 19.4$ & $75.8 \pm 7.3$ & $64.0 \pm 15.6$ & $74.5 \pm 10.6$ \\
R0 & $57.3 \pm 14.6$ & $67.1 \pm 20.4$ & $73.2 \pm 14.0$ & $71.5 \pm 12.3$ \\
R1 & $59.6 \pm 16.2$ & $65.3 \pm 20.0$ & $73.0 \pm 18.9$ & $72.9 \pm 12.7$ \\
R2 & $61.4 \pm 18.0$ & $57.2 \pm 21.5$ & $47.2 \pm 24.6$ & $68.1 \pm 14.4$ \\
\hline
\end{tabular}

Data are expressed as mean $\pm \mathrm{SD}$. There was no difference among groups. R0: at the beginning of reperfusion, R1: one hour after beginning of reperfusion, R2: two hours after beginning of reperfusion.

Table 2. Tidal Volume, Respiratory Rate and End-tidal Concentration of Isoflurane

\begin{tabular}{ccccc}
\hline & Group I & Group II & Group III & Group IV \\
\hline $\begin{array}{l}\text { Tidal volume (ml/kg) } \\
\text { Respiratory rates (/min) }\end{array}$ & $15.5 \pm 1.7$ & $15.0 \pm 1.6$ & $15.9 \pm 2.2$ & $14.8 \pm 2.1$ \\
Baseline & $39.4 \pm 4.4$ & $41.0 \pm 4.6$ & $42.7 \pm 5.9$ & $39.3 \pm 3.7$ \\
R0 & $40.3 \pm 3.8$ & $41.7 \pm 5.3$ & $44.6 \pm 6.4$ & $42.2 \pm 4.9$ \\
R1 & $41.7 \pm 3.8$ & $43.1 \pm 5.3$ & $46.8 \pm 6.0$ & $43.9 \pm 5.4$ \\
R2 & $41.2 \pm 3.9$ & $43.5 \pm 4.2$ & $50.6 \pm 6.3$ & $45.0 \pm 6.0$ \\
E iso (\%) & & & \\
Baseline & $0.49 \pm 0.39$ & $0.43 \pm 0.16$ & $0.39 \pm 0.23$ & $0.42 \pm 0.28$ \\
R0 & $0.30 \pm 0.32$ & $0.38 \pm 0.20$ & $0.51 \pm 0.30$ & $0.46 \pm 0.20$ \\
R1 & $0.35 \pm 0.28$ & $0.40 \pm 0.17$ & $0.40 \pm 0.36$ & $0.44 \pm 0.19$ \\
R2 & $0.31 \pm 0.31$ & $0.34 \pm 0.24$ & $0.40 \pm 0.24$ \\
\hline
\end{tabular}

Data are expressed as mean $\pm \mathrm{SD}$. Tidal volumes are the set values during baseline period and they were not changed throughout the experiment. There was no difference among groups. $\mathrm{E}_{\mathrm{T}}$ iso: end-tidal concentration of isoflurane, R0: at the beginning of reperfusion, R1: one hour after beginning of reperfusion, R2: two hours after beginning of reperfusion. 
Table 3. The Changes in Arterial Blood Gas Analysis $\left(\mathrm{F}_{\mathrm{I}} \mathrm{O}_{2}=1.0\right)$

\begin{tabular}{|c|c|c|c|c|}
\hline \multirow[b]{2}{*}{ PH } & \multicolumn{4}{|c|}{ ABGA } \\
\hline & Group I & Group II & Group III & Group IV \\
\hline Baseline & $7.30 \pm 0.09$ & $7.38 \pm 0.08$ & $7.36 \pm 0.09$ & $7.36 \pm 0.07$ \\
\hline $\mathrm{R}-0$ & $7.23 \pm 0.11$ & $7.28 \pm 0.13$ & $7.23 \pm 0.13$ & $7.26 \pm 0.11$ \\
\hline $\mathrm{R}-1$ & $7.23 \pm 0.08$ & $7.26 \pm 0.15$ & $7.09 \pm 0.12$ & $7.22 \pm 0.11$ \\
\hline $\mathrm{R}-2$ & $7.25 \pm 0.09$ & $7.25 \pm 0.20$ & $7.00 \pm 0.18$ & $7.18 \pm 0.18$ \\
\hline $\mathrm{PaCO}_{2}(\mathrm{mmHg})$ & Group I & Group II & Group III* & Group $\mathrm{IV}^{\dagger}$ \\
\hline Baseline & $37.1 \pm 6.5$ & $37.4 \pm 7.7$ & $37.0 \pm 5.6$ & $38.2 \pm 7.2$ \\
\hline $\mathrm{R}-0$ & $38.3 \pm 6.4$ & $39.0 \pm 4.3$ & $44.4 \pm 3.9$ & $43.2 \pm 11.0$ \\
\hline $\mathrm{R}-1$ & $37.9 \pm 4.5$ & $38.2 \pm 4.2$ & $53.6 \pm 8.6$ & $42.8 \pm 6.9$ \\
\hline $\mathrm{R}-2$ & $36.8 \pm 4.8$ & $34.5 \pm 5.8$ & $56.8 \pm 7.3$ & $45.9 \pm 8.7$ \\
\hline $\mathrm{PaO}_{2}(\mathrm{mmHg})$ & Group I & Group II & Group III* & Group $\mathrm{IV}^{\dagger}$ \\
\hline Baseline & $448.1 \pm 52.2$ & $471.8 \pm 55.5$ & $450.6 \pm 66.9$ & $470.4 \pm 78.3$ \\
\hline $\mathrm{R}-0$ & $381.5 \pm 116.2$ & $413.7 \pm 96.5$ & $133.8 \pm 87.2$ & $237.1 \pm 141.0$ \\
\hline $\mathrm{R}-1$ & $399.4 \pm 101.4$ & $430.8 \pm 77.7$ & $73.7 \pm 18.3$ & $220.7 \pm 153.6$ \\
\hline $\mathrm{R}-2$ & $451.8 \pm 70.2$ & $476.0 \pm 76.1$ & $61.8 \pm 9.8$ & $230.8 \pm 167.4$ \\
\hline
\end{tabular}

Data are expressed as mean $\pm \mathrm{SD}$. ABGA was performed five minutes after occluding right hilum to assess the isolated function of left lung. There is the tendency to decrease in $\mathrm{pH}$ and $\mathrm{PaO}_{2}$ and to increase in $\mathrm{PaCO}_{2}$ during reperfusion. The severest response occurred in group III, followed by group IV. R-0: at the beginning of the reperfusion period, R-1: one hour after beginning reperfusion, R-2: two hours after beginning reperfusion. *significantly different compared with the values of groups I, II and IV $(\mathrm{P}<0.05)$. ${ }^{+}$Significantly different compared with the values of groups I, II and III $(\mathrm{P}<0.05)$.

\section{DISCUSSION}

The signs of pulmonary ischemia-reperfusion injury include hypoxemia, pulmonary edema and decrease in pulmonary compliance. The main underlying disorder in ischemia-reperfusion lung injury is pulmonary vascular endothelial dysfunction manifested by increased vascular permeability that may result in pulmonary edema. Pulmonary ischemia-reperfusion injury may be initiated by the sequestration of polymorphonuclear (PMN) leukocytes subsequent to the expression of vascular endothelial adhesion molecules and the activation of PMN in the pulmonary vascular beds. ${ }^{8)}$ However, some evidence which shows the presence of PMN is not necessary has been presented. ${ }^{7,9)}$ Several humoral mediators such as oxygen free radicals, cytokines, and protease also seems to be involved during ischemia-reperfusion injury.

In this study acidosis, hypoxemia, hypercapnia and increase in lung water fraction were observed after unilateral warm ischemiareperfusion of lung. There was no difference in arterial $\mathrm{pH}$ among the groups because bicarbonate was administered in case of severe metabolic acidosis. Hypercapnia, hypoxemia and the increase of lung water fraction were most prominent in group III. The increase in lung water fraction following the ischemia- reperfusion suggests
Table 4. Lung Water Fraction

\begin{tabular}{lccc}
\hline & $\begin{array}{c}\text { Right postcaval } \\
\text { lobe water } \\
\text { fraction (\%) }\end{array}$ & $\begin{array}{c}\text { Left lung water } \\
\text { fraction }(\%)\end{array}$ & $\begin{array}{c}\text { Percent change } \\
\text { in lung water } \\
\text { fraction }\end{array}$ \\
\hline Group I & $80.9 \pm 0.4$ & $82.6 \pm 0.8$ & $2.1 \pm 0.8$ \\
Group II & $80.7 \pm 0.7$ & $82.3 \pm 1.7$ & $2.0 \pm 1.7$ \\
Group III & $81.2 \pm 1.8$ & $86.3 \pm 2.0^{*}$ & $6.2 \pm 2.0^{*}$ \\
Group IV & $80.4 \pm 2.1$ & $83.4 \pm 2.1$ & $3.8 \pm 2.9$ \\
\hline
\end{tabular}

Data are expressed as mean \pm SD. Water fraction of right postcaval lobe resected before ischemia shows control values obtained before ischemia-reperfusion injury. Left lung was resected 2 hours after beginning of reperfusion. The values of group III were significantly higher than those of other groups $(*: \mathrm{P}<0.05)$.

pulmonary edema. It is noteworthy that frothy secretion was observed only in groups III and IV, and that the incidence was highest in group III; this coincides with the results of the changes in lung water fraction. All of these findings demonstrate ischemiareperfusion injury of the lung.

In reducing ischemic-reperfusion injury, there have been presented that lung conditions such as hypothermia, ${ }^{1,7)}$ state of inflation, ${ }^{2,3)}$ and leukocyte depletion ${ }^{10)}$ during procurement play important roles. ${ }^{11)}$ As for the pharmacologic additives, prosta- 
glandins, ${ }^{4-6)}$ oxygen free radical scavengers, ${ }^{5)}$ steroids, calcium channel blockers and platelet activating factor antagonists have been reported to be beneficial in ameliorating ischemia-reperfusion injury.

In the present study inflation of lung prior to ischemia resulted in the excellent prevention of ischemia-reperfusion injury. The protective mechanism of pulmonary inflation is not clear yet. The surfactant mechanism which is vital in decreasing surface tension, promoting alveolar stability and preventing atelectasis, is one of suggested. Hildebran et al. ${ }^{12)}$ showed that air inflation to total lung capacity is a major physiologic stimulus to the release of lung surfactant into the alveolar space. Faridy ${ }^{13)}$ reported that lung distension enhanced the release of surfactant from type II pneumocytes, and that this process was markedly temperature dependent. It was reported that surfactant instillation was as effective as lung inflation on protecting lung from ischemiareperfusion injury. ${ }^{14)}$ It suggests that the state of deflation is an essential causative factor mediating the development of ischemiareperfusion injury.

Sakuma et al. ${ }^{7}$ presented electron microscopic findings showing capillary endothelial and alveolar epithelial injury in the lung reperfused after 4 hour-warm ischemia at the deflated state. They hypothesized that the injury during warm ischemia with lung deflated may have occurred in part because of active reorganization of the endothelial cytoskeleton, resulting in a marked increase in the gaps between endothelial cell junctions. Clinically, the beneficial effect of donor hyperinflation may be exerted through a more efficacious pulmonary artery flush that involves pulmonary vasodilation, avoidance of atelectasis, and conservation of donor lungs by prevention of alveolar collapse during hypothermic storage. ${ }^{3)}$ Regarding the significance of gas composition used for lung inflation, there are conflicting reports. Weder and coworkers described better preservation of a lung inflated with $100 \%$ oxygen compared with that inflated with room air or $100 \%$ nitrogen during 24 hours of cold ischemia $\left(10^{\circ} \mathrm{C}\right)$ in a rabbit model. ${ }^{15)}$ On the other hand, pulmonary inflation with $100 \%$ nitrogen during warm ischemia was also reported to be highly beneficial to lung preservation, and these results suggested that the protective effects were from the inflation itself, and not from the use of oxygen as a metabolic substrate during warm ischemia. ${ }^{7,16)}$

In this point of view, prevention of lung collapse during the ischemic period is very important in preserving the pulmonary function. ${ }^{3,17)}$ Veith et al. ${ }^{18)}$ demonstrated that the collapsed, nonventilated lung could tolerate only one-half hour of ischemia whereas the ischemic lung could still function perfectly after two hours of ventilation or after three hours of continuous inflation. Fonkalsrud et al. ${ }^{19)}$ reported that cyclic ventilation of the ischemic canine lung with $5 \mathrm{cmH}_{2} \mathrm{O}$ PEEP increased the length of survival more than five fold when compared to dogs treated by continuous expansion or cyclic ventilation without PEEP. Concerning the effect of lung inflation, our results showing excellent pulmonary protection by brief inflation before ischemia coincide with those of other investigators.

Regarding the protective effect of $\mathrm{PGI}_{2}$, we obtained favorable results only in collapsed groups (group III, IV). This is contrary to our previous study. ${ }^{20)}$ Our previous study on the effect of $\mathrm{PGI}_{2}$ against pulmonary ischemia-reperfusion injury failed to reveal the protective effect of $\mathrm{PGI}_{2}$. We suppose that the negative results of our previous study were due to $\beta$ error.

Although there are some conflicting results, ${ }^{6,20,21)}$ many investigators have reported $\mathrm{PGI}_{2}$ as one of the drugs that plays a significant role in reducing ischemia-reperfusion injury. ${ }^{4,5,22)}$ With its properties as pulmonary vasodilator, the majority of centers use $\mathrm{PGI}_{2}$ during single flush techniques as an adjuvant to the procedure, in order to counteract the possibility of reflex pulmonary vasoconstriction from the cold flush and to allow the uniform distribution of perfusate throughout the lungs. ${ }^{11)}$ In addition to strong pulmonary vasodilation, ${ }^{23)} \mathrm{PGI}_{2}$ causes cytoprotection and inhibits platelet aggregation and polymorphonuclear leukocytes adherence. ${ }^{24,25)}$ It also stabilizes the lysosomal membrane. ${ }^{26)}$ These effects related to pulmonary preservation results from an increase in c-AMP caused by the activation of adenylate cyclase. ${ }^{27)}$

In this experiment $\mathrm{PGI}_{2}$ did not work in the expanded lung. The authors thought that the beneficial effect of $\mathrm{PGI}_{2}$ on ischemiareperfusion injury were masked by the protective effect of lung inflation. This coincides with the report by Puskas et al. ${ }^{3)}$ They revealed that donor hyperventilation and inflation to $30 \mathrm{cmH}_{2} \mathrm{O}$ before hypothermic storage provided excellent function of post-transplantation lung after 30 hours of preservation with or without $\mathrm{PGE}_{1}$ pretreatment. ${ }^{3)}$

The other possible reason of $\mathrm{PGI}_{2}$ 's ineffectiveness in expanded groups seems to be related with shifting of pulmonary blood flow by inflation of lungs and consequent decrease in the amount of $\mathrm{PGI}_{2}$ in pulmonary circulation. Because the half-life of $\mathrm{PGI}_{2}$ at body temperature is two to three minutes, the decrease in the $\mathrm{PGI}_{2}$ in pulmonary circulation just before inducing ischemia may result in diminished effect. Therefore, although many centers use $\mathrm{PGI}_{2}$ in their lung transplantation programs as a component of perfusate, we doubt the effectiveness of intravenous administration of $\mathrm{PGI}_{2}$ on pulmonary preservation if donor lung were stored inflated. 
As for the effect of volatile anesthetics on the ischemiareperfusion injury, different results were reported. Isoflurane and sevoflurane administered before ischemia can attenuate ischemiareperfusion induced injury in isolated rat lungs. ${ }^{28)}$ In an isolated rabbit lung model, isoflurane attenuated ischemia- reperfusion induced lung injury. ${ }^{29)}$ In contrast, Nielsen et al. ${ }^{30)}$ demonstrated an evidence that indicated volatile anesthetics have detrimental effects on lung injury induced by thoracic aorta occlusionreperfusion in a rabbit model. Because these reports presented contradictory results and some of them were not carried out in vivo, the effect of volatile anesthetics on ischemia-reperfusion model in vivo is not clear. In the current study, the influence of volatile anesthetics on the results seems to be ignorable because the end-tidal concentration of isoflurane was not different among groups.

In summary, expansion of the lungs with or without $\mathrm{PGI}_{2}$ provided equally excellent post-ischemic pulmonary function. In contrast, collapse of lung led to severer damage of lung. Although the effect of $\mathrm{PGI}_{2}$ was not prominent in expansion groups, $\mathrm{PGI}_{2}$ had some protective effect in collapsed lung. The results of this study suggests that alveolar collapse is more basic pathophysiology in pulmonary ischemia-reperfusion injury than other cellular and humoral mechanisms.

\section{REFERENCES}

1. Joseph WL, Morton DL: Influence of ischemia and hypothermia on the ability of the transplanted primate lung to provide immediate and total respiratory support. J Thorac Cardiovasc Surg 1971; 62: 752-62.

2. Fonkalsrud E, Sanchez M, Higashijima I, Gyepes M, Arima E: Evaluation of pulmonary function in the ischemic expanded canine lung. Surg Gynecol Obstet 1976; 142: 573-7.

3. Puskas JD, Hirai T, Christie N, Mayer E, Slutsky AS, Patterson GA: Reliable thirty-hour lung preservation by donor lung hyperinflation. J Thorac Cardiovasc Surg 1992; 104: 1075-83.

4. Hooper TL, Thomson DS, Jones MT, Cook L, Owen S, Wilkes $\mathrm{S}$, et al: Amelioration of lung ischemic injury with prostacyclin. Transplantation 1990; 49: 1031-5.

5. Yamashita C, Oobo H, Tsuji F, Tobe S, Yamamoto H, Nakamura $\mathrm{H}$, et al: Effect of prostaglandin $\mathrm{I}_{2}$ and superoxide dismutase on reperfusion injury of warm ischemic lung. Ann Thorac Surg 1992; 54: $921-4$.

6. Dammenhayn L, Yagyu K, Schfers HJ, Haverich A: The effect of prostacyclin on reperfusion injury after pulmonary ischemia. Transplant Proc 1989; 21: 1363.

7. Sakuma T, Takahashi K, Ohya N, Kajikawa O, Martin TR, Albertine $\mathrm{KH}$, et al: Ischemia-reperfusion lung injury in rabbits: mechanisms of injury and protection. Am J Physiol 1999; 276: L137-45.

8. Moore TM, Khimenko P, Adkins WK, Miyasaka M, Taylor AE: Adhesion molecules contribute to ischemia and reperfusioninduced injury in the isolated rat lung. J Appl Physiol 1995; 78: 2245-52.

9. Deeb GM, Grum CM, Lynch MJ, Guynn TP, Gallagher KP, Ljungman AG, et al: Neutrophils are not necessary for induction of ischemia-reperfusion lung injury. J Appl Physiol 1990; 68: 374-81.

10. Pillai R, Bando K, Schueler S, Zebley M, Reitz BA, Baumgartner WA: Leukocyte depletion results in excellent heart-lung function after 12 hours of storage. Ann Thorac Surg 1990; 50: 211-4.

11. Kirk AJB, Colquhoun IW, Dark J: Lung preservation: a review of current practice and future directions. Ann Thorac Surg 1993; 56: $990-1000$.

12. Hildebran JN, Goerke J, Clements JA: Surfactant release in excised rat lung is stimulated by air inflation J Appl Physiol 1981; 51: 905-10.

13. Faridy EE: Effect of distension on release of surfactant in excised dogs lungs. Respir Physiol 1976; 27: 99-114.

14. Srinvasan HB, Vogel SM, Vidyasagar D, Malik AB: Protective effect of lung inflation in reperfusion-induced lung microvascular injury. Am J Physiol Heart Circ Physiol 2000; 278: H951-7.

15. Weder W, Harper B, Shimokawa S, Miyoshi S, Date H, Schreinemakers $\mathrm{H}$, et al: Influence of intraalveolar oxygen concentration on lung preservation in a rabbit model. $\mathrm{J}$ Thorac Cardiovasc Surg 1991; 101: 1037-43.

16 Watanabe A, Kawaharada N, Kusajima K, Komatsu S, Abe T, Takahashi $\mathrm{H}$ : Influence of oxygen in inflation gas during lung ischemia on ischemia-reperfusion injury. J Thorac Cardiovasc Surg 1997; 114: 332-8.

17. Stevens GH, Sanchez MM, Chappell GL: Enhancement of lung preservation by prevention of lung collapse. J Surg Res 1973; 14 : 400-5.

18. Veith FJ, Sinha SBP, Graves JS, Boley SJ, Dougherty JC: Ischemic tolerance of the lung-The effect of ventilation and inflation. $\mathrm{J}$ Thorac Cardiovasc Surg 1971; 61: 804-10.

19. Fonkalsrud EW, Sanchez M, Lassaletta L, Smeesters C, Higashijima I: Extended preservation of the ischemic canine lung by ventilation with PEEP. J Surg Res 1975; 18: 437-45.

20. Kim K, Oh Y-S: The effects of prostacyclin on $\mathrm{PaO}_{2}$, pulmonary vascular resistance and pulmonary water content in the experimental canine undergoing pulmonary ischemia-reperfusion injury. Korean J Anesthesiol 1999; 36: 319-26.

21. Hooper TL, Fetherston GJ, Flecknell PA, Dark JH, McGregor CGA: The use of prostacyclin analog, iloprost, as an adjunct to pulmonary preservation with Euro-Collins solution. Transplantation 1990; 49: 495-9.

22. Jurmann MJ, Dammenhayn L, Schfers H-J, Wahlers T, Fieguth $\mathrm{H}-\mathrm{G}$, Haverich A: Prostacyclin as an additive to single crystalloid flush: improved pulmonary preservation in heart-lung transplantation. Transplant Proc 1987; 19: 4103-4. 
23. Mulvin D, Jones K, Howard R, Grosso M, Repine J, Johnston M: The effect of prostacyclin as a constituent of a preservation solution in protecting lungs from ischemic injury because of its vasodilatory properties. Transplantation 1990; 49: 828-30.

24. Robert A: Cytoprotection by prostaglandins. Gastroenterology 1979; 77: 761-7.

25. Jones G, Hurley JV: The effect of prostacyclin on the adhesion of leukocytes to injured vascular endothelium. J Pathol 1984; 142: 51-9.

26. Fantone JC, Marasco WA, Elgas LJ, Ward PA: Stimulus specificity of prostaglandin inhibition of rabbit polymorphonuclear leukocyte lysosomal enzyme release and superoxide anion production. Am J Pathol 1984; 115: 9-16.

27. Jiang XW, Kambara K, Gotoh N, Nishigaki K, Fujiwara H: Effects of low-dose beraprost sodium, a stable prostaglandin $I_{2}$ analogue, on reperfusion injury to rabbit lungs. Am J Respir Crit Care Med 1998; 158: 1669-75.

28. Liu R, Ishibe $\mathrm{Y}$, Ueda M: Isoflurane-sevoflurane administration before ischemia attenuates ischemia-reperfusion-induced injury in isolated rat lungs. Anesthesiology 2000; 92: 833-40.

29. Liu R, Ishibe Y, Ueda M, Hang Y: Isoflurane administration before ischemia and during reperfusion attenuates ischemia/reperfusioninduced injury of isolated rabbit lungs. Anesth Analg 1999; 89:561-5.

30. Nielsen VG, Baird MS, McAdams ML, Freeman BA: Desflurane increases pulmonary alveolar-capillary membrane permeability after aortic occlusion-reperfusion in rabbits: evidence of oxidantmediated lung injury. Anesthesiology 1998; 88: 1524-34. 